\title{
A systematic review and meta-analysis of HIV associated neurocognitive disorders (HAND) among people with HIV in Ethiopia
}

\author{
Yosef Zenebe $^{1^{*}}$ (D) , Baye Akele ${ }^{2}$, Mulugeta W/Selassie ${ }^{3}$ and Mogesie Necho
}

\begin{abstract}
Background: Ethiopia, being in the Sub Saharan region of Africa, is one of the countries with a substantial burden of HIV infection. Because of the high burden of HIV and poor health care settings, HAND is prevalent as demonstrated in various cross-sectional studies. However, no review has been conducted to report the consolidated magnitude of HAND among people with HIV in Ethiopia. Therefore, this systematic review and meta-analysis aimed to estimate the prevalence of HAND in Ethiopia.

Methods: Following the PRISMA guidelines, we systematically reviewed and meta-analyzed studies that investigated the prevalence of HAND in Ethiopia from PubMed, Google Scholar, Science Direct, HINARI, EMBASE, and Cochrane library databases. We also looked at the reference lists of the included studies to include other relevant studies. Subgroup analysis was performed based on publication year, study location, and sample size. Heterogeneity across studies was evaluated using the 12 test. Potential publication bias was assessed using Egger's test and visual inspection of symmetry in the funnel plots.
\end{abstract}

Results: In the present meta-analysis, 627 articles were initially identified and evaluated. Of these, 8 studies that met the inclusion criteria were included in the final analysis. The pooled prevalence of HAND in people with HIV in Ethiopia was 39.15\% (95\% Cl 29.36, 48.94). The highest prevalence observed in the Southern Nations, Nationalities, and Peoples' Region (SNNPR) with 53.20\% (95\% Cl 25.96, 80.44) followed by others $34.87 \%$ (Tigray, Addis Ababa, and Oromia) $(95 \% \mathrm{Cl} 33.49,36.24)$ and Amhara $34.07 \%$ (95\% Cl 25.39, 42.74). The funnel plot was asymmetrical. However, Egger's regression tests provided no evidence of publication bias in the prevalence of HAND.

Conclusion: In this meta-analysis, the pooled prevalence of HAND, in Ethiopia, was high. Older age, substance use, advanced stages of the disease, and lack of education were the main determinants of HAND in Ethiopia. Health education, early screening of people with HIV, and training of health professionals working in hospitals on HAND are highly recommended.

Keywords: Ethiopia, Systematic review, HAND, HIV/AIDS

*Correspondence: yosef.zenebe79@gmail.com; yosef.zenebe@wu.edu.et 1 Department of Psychiatry, College of Medicine and Health Sciences, Wollo University, Dessie, Ethiopia

Full list of author information is available at the end of the article

\section{Background}

Human immunodeficiency virus (HIV) is neuro-virulent and often causes brain impairment, especially at advanced stages of HIV infection. Subcortical brain structures are the most frequently affected areas of the brain by HIV; thus the resulting changes in these structures ultimately cause a spectrum of disorders that are collectively referred to as HAND $[1,2]$. HAND covers original author(s) and the source, provide a link to the Creative Commons licence, and indicate if changes were made. The images or other third party material in this article are included in the article's Creative Commons licence, unless indicated otherwise in a credit line to the material. If material is not included in the article's Creative Commons licence and your intended use is not permitted by statutory regulation or exceeds the permitted use, you will need to obtain permission directly from the copyright holder. To view a copy of this licence, visit http://creativecommons.org/licenses/by/4.0/. The Creative Commons Public Domain Dedication waiver (http://creativeco mmons.org/publicdomain/zero/1.0/) applies to the data made available in this article, unless otherwise stated in a credit line to the data. 
three disorders ranging in severity from asymptomatic neurocognitive impairment (ANI) to mild neurocognitive disorder (MND) to HIV-associated dementia (HAD) [3-7].These disorders have a negative impact not only on routine daily activities such as cleaning, cooking, money calculation, driving, etc. but also on adherence to treatment and social and professional integration $[8,9]$.

Africa, especially its sub Saharan region, is one of the continents that are sternly affected by HIV. Ethiopia, being in the sub-Saharan region, is one of the countries with a substantial burden of HIV infection [10]. Because of the high burden of HIV and poor health care settings, HAND is prevalent as demonstrated in various crosssectional studies. A study conducted in Addis Ababa by Araya et al. [11] revealed that $35.6 \%$ of the study participants had developed HIV-associated neurocognitive disorder (HAND). Another study conducted at Ayder Hospital in the Tigray region of Ethiopia demonstrated that $33.3 \%$ of HIV-positive Adults on ART experienced HAND. A few more cross-sectional facility-based studies have failed to map the real burden of HAND [12].

There are many predictors of HAND in patients with HIV infection. These include; CD4 count, the onset of opportunistic infection, low hemoglobin concentration, Body mass index, advanced age, female sex, level of education, income level, social support, medical comorbidities, intravenous drug use, HIV medication adherence, self-reported alcohol use, khat chewing, lifetime use of tobacco, marital status and unemployment status [11, 13-21].

Although few facility-based cross-sectional studies have been conducted previously in different parts of Ethiopia on HAND, the pooled prevalence of the problem in Ethiopia is unknown. Additionally, the risk factors reported by different researchers have been inconsistent. This might be due to social, cultural, and lifestyle differences among the study subjects across the country. This systematic review and meta-analysis aimed to determine the pooled prevalence of HAND in Ethiopia and the determinant factors influencing it. This study may also draw a new hypothesis based on this heterogeneity. Hence, this research is of paramount importance in providing clear crystal evidence to policymakers, researchers, and clinicians to ease their work on HAND.

\section{Methods}

\section{Search strategy}

The present systematic review and meta-analysis were conducted based on a review of different types of literature. The international databases including PubMed, Google Scholar, Science Direct, HINARI, EMBASE, and Cochrane library were exhaustively searched. In addition, reference lists of previously identified articles were also searched to retrieve more relevant studies. Preferred Reporting Items for Systematic Reviews and Meta-Analyses (PRISMA) [22] was used as a guideline for rigor. The search was carried out using the following keywords by the Boolean operator: "Prevalence" OR "Epidemiology" AND "neuro-cognitive impairment" OR "HIV Associated Neurocognitive Disorders" OR "HAND” OR "Neurocognitive Disorders" OR "Cognitive disorders" OR "Cognitive impairment" AND "HIV/AIDS" AND "Ethiopia." The included studies were published from January 2014 to April 16, 2021.

\section{Eligibility criteria}

All original studies published until April 16, 2021, were included in this review. An article was included if it met the following criteria: (1) the study was conducted in Adults, (2) the study design was observational (cross-sectional and case-control study design), (3) the outcome of interest was HAND, (4) human studies and (5) conducted in Ethiopia. We excluded editorials and reviews.

\section{Data extraction}

Extractions of the required data from the studies and the full texts of the articles were assessed by two authors ( $\mathrm{YZ}$ and $\mathrm{MN}$ ). Any discrepancy was resolved by discussion, and the following information was independently extracted from each study by two authors ( $\mathrm{YZ}$ and $\mathrm{MN}$ ) using a standardized data extraction format: primary author, publication year, region of the study (study site in the country), sample size, screening tool used, response rate and reported prevalence of HAND.

\section{Quality assessment}

The Joanna Briggs institute quality assessment tool was used to assess the quality of the studies included in this meta-analysis [23]. The scoring of each publication was performed using the frequency scales that were answered as yes, no, unclear, and not applicable. The total quality score for each study was calculated based on the total number of positive scores.

\section{Statistical analysis}

In the current meta-analysis, all statistical analyses were conducted using comprehensive meta-analysis software version 3 [24]. The prevalence rates from individual studies were pooled using a random-effects meta-analysis [25]. I2 statistics have been used to assess heterogeneity between studies [25]. The values of I2 statistics such as $75 \%, 50 \%$, and 25\%, represented high, medium and low heterogeneity respectively [26]. The publication year, study location and sample size of the studies were used to evaluate the possible sources of heterogeneity across the studies. Publication bias was 
assessed using funnel plots and Egger's regression tests. For all analyses, the P-value for statistical significance was set at 0.05 .

\section{Definition of terms}

Advanced stages of the diseases: People living with HIV who were in WHO clinical stage $\mathrm{T} 3$ and T4.

HAND: It included three disorders such as asymptomatic neurocognitive impairment (ANI), mild neurocognitive disorder (MND) and HIV-associated dementia (HAD) [3-5, 27, 28].

Older age: People living with HIV whose age was 40 years or more.

\section{Results}

Search result

The electronic database search retrieved 627 records, of which 115 were duplicates. The titles and abstracts of 512 articles were assessed, and 353 articles were removed. Therefore, a full-text of 159 publications was retained for further evaluation, 8 of which were qualified for the present systematic review and meta-analysis (Fig. 1).

\section{Characteristics of studies included}

In this review, a total of 8 studies were included in the final meta-analysis conducted in five regions in Ethiopia representing 3529 participants. Of the 8 studies, three were published from 2014 to 2017 years $[12,15,28]$ and

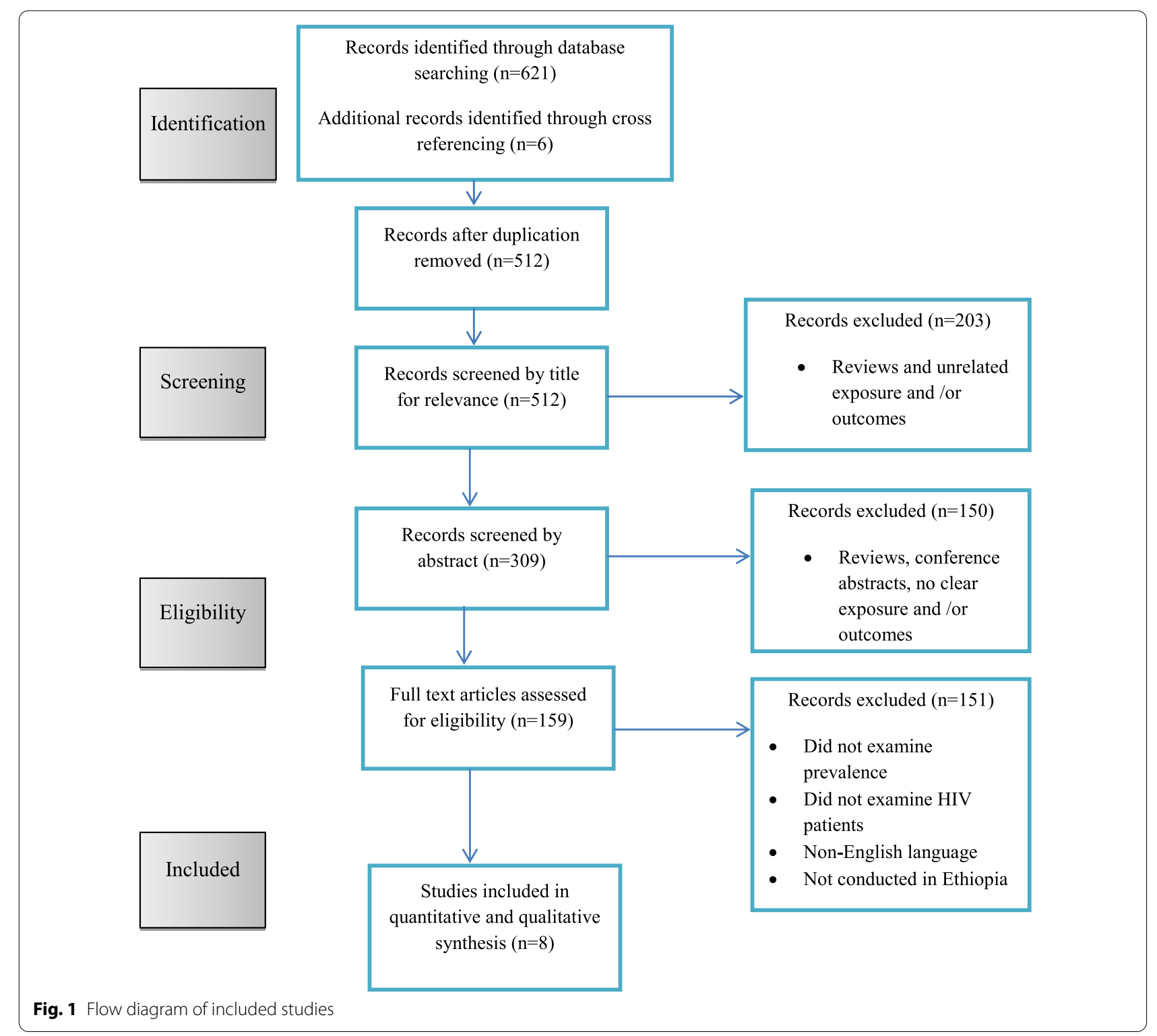


five were published from 2019 to 2021 years [11, 21, 2931]. Three studies were from Tigray, Addis Ababa, and Oromia [11, 12, 31], three were from Amhara [15, 28, 30] and two were from SNNPR $[21,29]$. Three studies used a sample size of less than 400 [12, 29, 31], and five of the studies used a sample size of more than $400[11,15,21$, $28,30]$ (Table 1).

\section{Quality of included studies}

Based on the Joanna Briggs institute quality evaluation checklist, the articles involved in the final analysis had a mean quality score of 8.75 ranging from seven to nine. Seven studies $(87.5 \%)$ were high-quality studies (score $\geq 8.75$ ) and the remaining one was moderate quality article (scored between 6 and 8.75). None of the articles were found to be of poor quality (Table 2).

\section{The prevalence of HAND among People with HIV}

There was significant heterogeneity between the studies $(\mathrm{I} 2=100 \%, \mathrm{P}<0.001)$, therefore, we used random-effects models to estimate the prevalence of HAND in people with HIV. The overall pooled estimated (random effects models) of the prevalence of HAND in people with HIV was $39.15 \%$ (95\% CI 29.36-48.94) (Fig. 2). The pooled estimate of the prevalence was higher in the SNNPR region than in the Amhara region (53.20\%; 95\% CI 25.96, 80.44 vs. $34.07 \%$; $95 \%$ CI 25.39, 42.74) (Table 3).

Table 1 The characteristics of studies included in the systematic review and meta-analysis of HAND in Ethiopia

\begin{tabular}{|c|c|c|c|c|c|c|c|}
\hline Author, publication year & Location of the study & Study setting & Study design & Sample size & Tool used & Prevalence & $\begin{array}{l}\text { Number } \\
\text { of cases }\end{array}$ \\
\hline Belete et al. 2017 & Mekelle, Ethiopia & Health institution & CS & 254 & $I H D S \leq 9.5$ & $33.3 \%$ & 85 \\
\hline Tsegaw et al. 2017 & South Wollo, Ethiopia & Health institution & CS & 593 & $\| \mathrm{HDS} \leq 9.5$ & $36.4 \%$ & 216 \\
\hline Animut et al. 2019 & Gamo Gofa, Ethiopia & Health institution & CS & 684 & $\operatorname{HDS}<9.5$ & $67.1 \%$ & 459 \\
\hline Araya et al. 2020 & Addis Ababa, Ethiopia & Health institution & CS & 581 & $\operatorname{HDS} \leq 9.5$ & $35.6 \%$ & 207 \\
\hline Yitbarek et al. 2019 & Jimma, Ethiopia & Health institution & CS & 328 & $\| H D S \leq 10$ & $35.7 \%$ & 117 \\
\hline Mossie et al. 2014 & Debre Markos, Ethiopia & Health institution & $C S$ & 423 & $\operatorname{HDS} \leq 10$ & $24.8 \%$ & 105 \\
\hline Wubetu et al. 2021 & Debre Berhan, Ethiopia & Health institution & CS & 422 & MMSE $<25$ & $41 \%$ & 173 \\
\hline Salahuddin et al. 2020 & Mizan-Aman, Ethiopia & Health institution & CS & 244 & $\mid H D S \leq 10$ & $39.3 \%$ & 96 \\
\hline
\end{tabular}

CS cross-sectional, HAND HIV Associated Neurocognitive Disorders, IHDS International HIV Dementia Scale, MMSE Mini Mental State Examination

Table 2 Qualities of studies included in the systematic review and meta-analysis

\begin{tabular}{|c|c|c|c|c|c|c|c|c|c|c|}
\hline \multirow[t]{2}{*}{ Study name } & \multicolumn{10}{|c|}{ Response } \\
\hline & Q1 & Q2 & Q3 & Q4 & Q5 & Q6 & Q7 & Q8 & Q9 & $\overline{\text { Total }}$ \\
\hline Belete et al. 2017 & Y & Y & Y & Y & Y & Y & Y & Y & Y & 9 \\
\hline Tsegaw et al. 2017 & Y & Y & Y & Y & Y & Y & Y & Y & Y & 9 \\
\hline Animut et al. 2019 & Y & Y & Y & Y & Y & Y & Y & Y & Y & 9 \\
\hline Araya et al. 2020 & Y & Y & Y & Y & Y & Y & Y & Y & Y & 9 \\
\hline Yitbarek et al. 2019 & Y & Y & Y & Y & Y & Y & Y & Y & Y & 9 \\
\hline Mossie et al. 2014 & Y & Y & Y & Y & Y & Y & Y & Y & Y & 9 \\
\hline Wubetu et al. 2021 & Y & Y & Y & Y & Y & Y & Y & Y & $Y$ & 9 \\
\hline Salahuddin et al. 2020 & Y & $\mathrm{N}$ & $U$ & Y & Y & Y & Y & Y & Y & 7 \\
\hline
\end{tabular}

Q1-Q9 represents questions used to assess the quality of included studies, which are listed below

Q1. Was the sample frame appropriate to address the target populations?

Q2. Were the study participants sampled in appropriate way?

Q3. Was the sample size adequate?

Q4. Were the study subjects and setting described in details?

Q5. Was the data analysis conducted with sufficient coverage of the identified sample? Q6. Was a valid method used in the identification of conditions?

Q7. Was the condition measured in a standard, reliable way for all participants?

Q8. Was there an appropriate statistical analysis?

Q9. Was the response rate adequate, and if not, was the low response rate managed appropriately?

$N$ no, $N A$ not applicable, $U$ unclear, $Y$ yes 


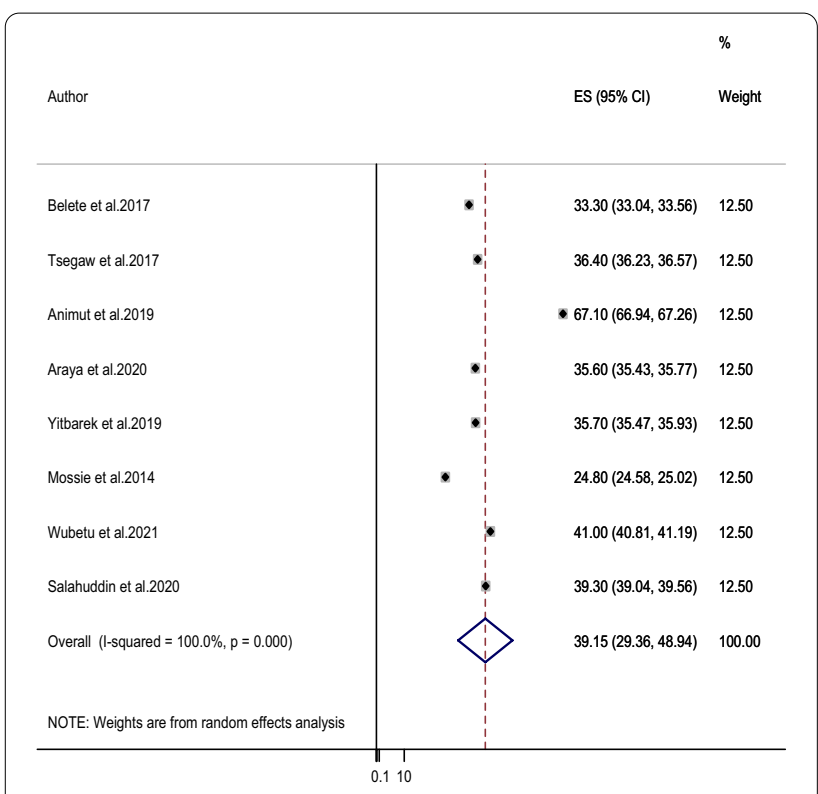

Fig. 2 The forest plot of the prevalence of HAND among People with HIV in Ethiopia: a meta-analysis

\section{Subgroup analysis among people living with HIV}

In addition, subgroup analysis was performed based on the year of publication, location of the study, and sample size. Regarding the publication year, the prevalence of HAND was slightly higher in studies published from 2019 to 2021 years $43.74 \%$ (30.32, 57.16) followed by studies from 2014 to 2017 years $31.50 \%$ (24.32, 38.68). Accordingly, the highest prevalence was observed in SNNPR with a prevalence of $53.20 \%(25.96,80.44)$ followed by others (Tigray, Addis Ababa, and Oromia) (34.87\%, 33.49, $36.24)$ and the Amhara region (34.07\%, 25.39, 42.74).The prevalence of HAND was $40.98 \%$ (95\% CI 26.64, 55.32) for studies that used a sample size of more than 400 and it was $36.10 \%$ (95\% CI 32.83, 39.37) for studies that used a sample size of less than 400 (Table 3).

\section{Sensitivity analysis of HAND among people living with HIV} Sensitivity analysis was performed to identify whether one or more of the eight studies had out-weighted the average prevalence of HAND among people living with HIV. However, the result showed that there was no single influential study since the $95 \% \mathrm{CI}$ interval obtained when each of the eight studies was excluded at a time is within the $95 \% \mathrm{CI}$ interval of the overall result (Fig. 3).

\section{Funnel plot of the risk of publication bias for HAND among people with HIV}

Qualitatively, the funnel plot was asymmetric, supporting the presence of publication bias by visual inspection. However; quantitatively, Egger regression tests provided no evidence of substantial publication bias for the prevalence of HAND among people with HIV in Ethiopia $(\mathrm{P}=0.201)$ (Fig. 4).

\section{A systematic review and meta-analysis of associated factors for HAND in Ethiopia}

Older age, having no education (being illiterate), having a primary education, being unemployed, having a low income, having a body mass index of $16 \mathrm{~kg} / \mathrm{m}^{2}$, poor social support, substance use, having a comorbid opportunistic infection, comorbid depression, anxiety, and advanced disease stage were significant and positive predictors of HAND (Table 4). The factors most frequently associated with HAND in People with HIV were older age $[15,28-31]$, being illiterate $[11,15,28]$, substance use $[11,15,29,31]$, and advanced stage of the disease [12, 21, 31].

Table 3 A subgroup analysis among people living with HIV

\begin{tabular}{|c|c|c|c|c|c|}
\hline \multirow[t]{2}{*}{ Subgroup } & \multirow[t]{2}{*}{ Number of studies } & \multicolumn{2}{|l|}{ Estimates } & \multicolumn{2}{|c|}{ Heterogeneity } \\
\hline & & Prevalence (\%) & $95 \% \mathrm{Cl}$ & 12 & P-value \\
\hline \multicolumn{6}{|l|}{ Year of publication } \\
\hline 2014-2017 Years & 3 & 31.50 & $24.32,38.68$ & $100 \%$ & $<0.001$ \\
\hline 2019-2021 Years & 5 & 43.74 & $30.32,57.16$ & $100 \%$ & $<0.001$ \\
\hline \multicolumn{6}{|l|}{ Location of the study } \\
\hline Amhara & 3 & 34.07 & $25.39,42.74$ & $100 \%$ & $<0.001$ \\
\hline SNNPR & 2 & 53.20 & $25.96,80.44$ & $100 \%$ & $<0.001$ \\
\hline $\begin{array}{l}\text { Others (Tigray, Addis Ababa and } \\
\text { Oromia) }\end{array}$ & 3 & 34.87 & $33.49,36.24$ & $99.2 \%$ & $<0.001$ \\
\hline \multicolumn{6}{|l|}{ Sample size } \\
\hline Below 400 & 3 & 36.10 & $32.83,39.37$ & $99.8 \%$ & $<0.001$ \\
\hline Above 400 & 5 & 40.98 & $26.64,55.32$ & $100 \%$ & $<0.001$ \\
\hline
\end{tabular}




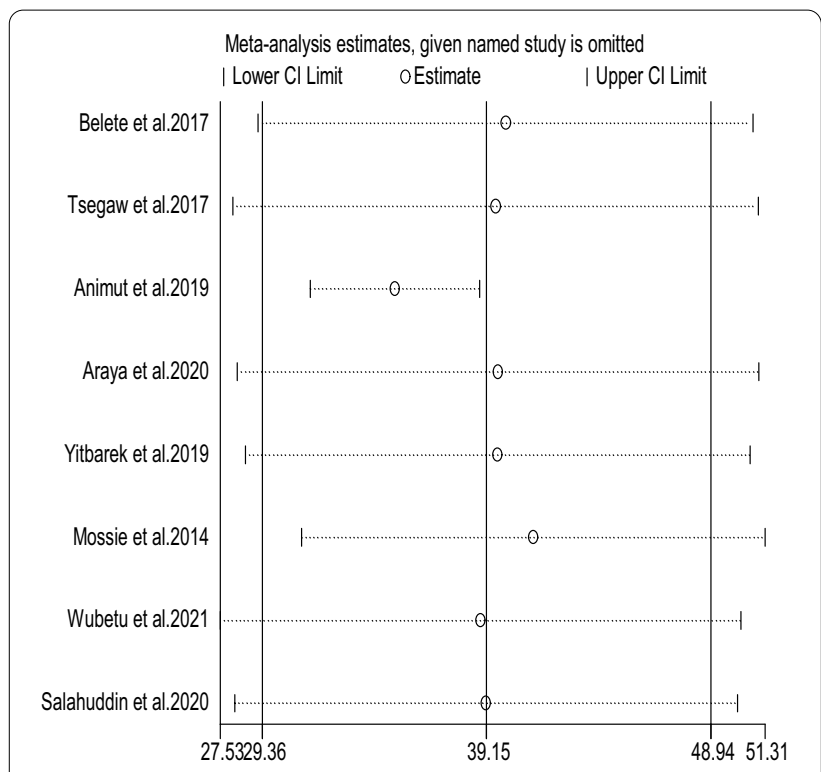

Fig. 3 Sensitivity analysis for the prevalence of HAND among people with HIV in Ethiopia

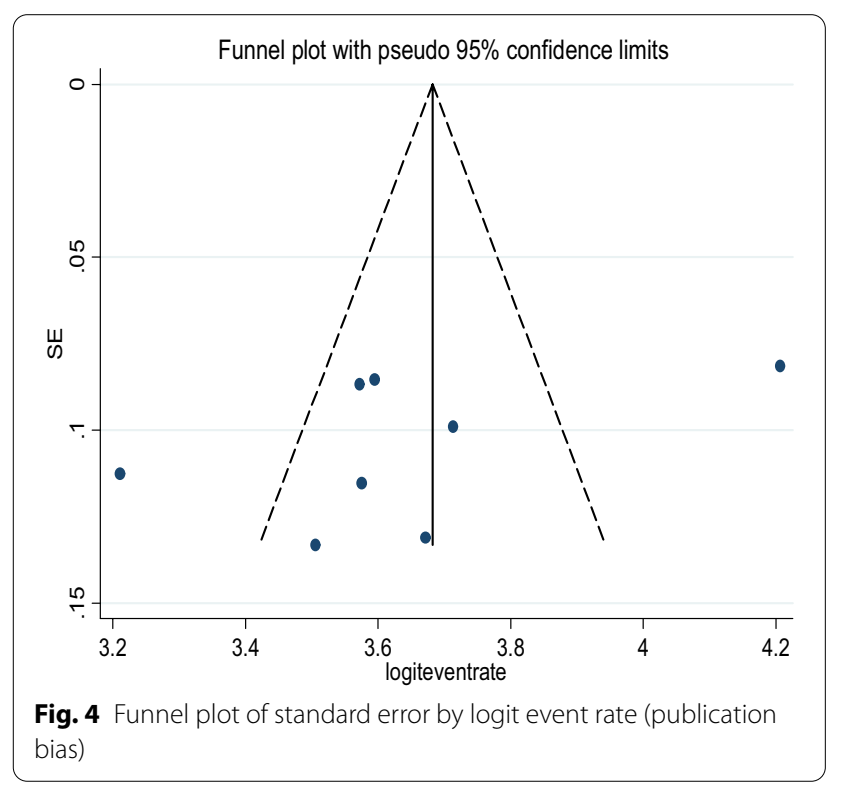

The pooled odds ratio of older people among the above mentioned studies was 2.97 (95\% CI 2.12, 3.82). This implied that people with old age were 2.97 times at higher risk of developing HAND than people with 18-25 years old. In addition, the pooled odds ratio for illiterate people for the three studies reported above was found to be 4.20 (95\% CI 3.12, 5.28). This showed that illiterate participants were 4.20 times more likely to develop HAND than participants with primary and secondary education.
Substance use was also an associated factor for the development of HAND with a pooled estimate odds ratio of 6.28 (95\% CI 0.73, 11.82). In addition, the advanced stage of the disease was also found to have a significant association with the development of HAND with an estimated pooled odds ratio of 4.45 (95\% CI 3.16, 5.74) (Table 5).

\section{Discussion}

To our knowledge, this is the first study to systematically search, select, and analyze the prevalence of HAND in Ethiopia, which was examined across 8 studies including 3529 participants. The pooled estimated prevalence of HAND was $39.15 \%$. Old age, lack of education, substance use and advanced stage of the disease were the main determinants of HAND.

The overall pooled prevalence of HAND in Ethiopia was 39.15 (95\% CI 29.36, 48.94). This finding was higher than the prevalence estimated in a systematic review and metaanalysis study conducted in sub-Saharan Africa among those on ART for 6 months was 30.39\% (95\% CI 13.1747.61\%) [10]. Nevertheless, some studies have verified that this pooled prevalence was lower than that in studies conducted in different countries such as $42.37 \%$ (95\% CI 32.18, $52.56 \%$ ) in sub-Saharan Africa pre-ART HIV patients [10], and $42.6 \%$ (95\% CI $39.7-45.5)$ in a global meta-analysis study [32]. This difference in findings may reflect differences in participants' characteristics, sample sizes and publication years. This review included People with HIV who had ART care follow-up in health institutions but other studies may include those people with HIV who did not have ART care follow-up. In addition, developing countries, including those in sub-Saharan Africa, are currently undergoing a demographic and epidemiological transition and the impact of population aging in sub-Saharan Africa will increase the burden of non-communicable and degenerative diseases in this region [33].The discrepancy may also be due to the screening tools. It is worth noting that the vast majority of the studies used the IHDS, which has shown by Milanini et al. [34] to be very poorly sensitive in a multi country East African population (Uganda, Kenya and Tanzania). The reliance of the IHDS in so many of these studies is a critical caveat for the overall meta-analysis; likely the meta-analysis estimate is too high.

In this systematic review and meta-analysis, random effect models have been used bearing in mind the chances of substantial heterogeneity between studies which were confirmed with the I2 test. In the subgroup analysis, the prevalence of HAND was slightly higher in studies published from 2019 to 2021 years; $43.74 \%$ than studies from 2014 to 2017 years; $31.50 \%$.

The pooled prevalence revealed clear differences in the prevalence of HAND among regions; studies from 
Table 4 A systematic review and meta-analysis of associated factors for HAND in Ethiopia

\begin{tabular}{|c|c|c|c|c|}
\hline Associated factors & Odds ratio(AOR) & $\begin{array}{l}\text { 95\% } \\
\text { confidence } \\
\text { interval }\end{array}$ & Strength of association & Author, year of publication \\
\hline Older age & 3.31 & $1.26,8.70$ & Strong and positive & Tsegaw et al. 2017 \\
\hline Age group of $41-64$ years & 3.1 & $1.3,7.4$ & Strong and positive & Yitbarek et al. 2019 \\
\hline Older age of 50 years or above & 4.25 & $1.05,17.18$ & Strong and positive & Mossie et al. 2014 \\
\hline Older individuals & 1.06 & $1.03,1.08$ & Weak and positive & Wubetu et al. 2021 \\
\hline Being older than 40 years & 2.81 & $1.11,7.15$ & Moderate and positive & Salahuddin et al. 2020 \\
\hline No formal education & 4.29 & $2.62,7.02$ & Strong and positive & Tsegaw et al. 2017 \\
\hline Being illiterate & 5.16 & $2.20,12.07$ & Strong and positive & Araya et al. 2020 \\
\hline Having no education & 3.11 & $1.37,7.04$ & Strong and positive & Mossie et al. 2014 \\
\hline Having a primary-level education & 3.27 & $1.46,7.29$ & Strong and positive & Araya et al. 2020 \\
\hline Being married & 0.377 & $0.21,0.67$ & Weak and negative & Animut et al. 2019 \\
\hline Unemployment status & 3.18 & $1.75,5.78$ & Strong and positive & Animut et al. 2019 \\
\hline Low monthly income & 4.22 & $2.02,8.81$ & Strong and positive & Wubetu et al. 2021 \\
\hline Body mass index $16 \mathrm{~kg} / \mathrm{m}^{2}$ & 4.39 & $1.60,12.02$ & Strong and positive & Animut et al. 2019 \\
\hline Having poor social support & 3.65 & $1.86,7.17$ & Strong and positive & Wubetu et al. 2021 \\
\hline Poor medication adherence & 1.49 & $1.01,2.18$ & Weak and positive & Tsegaw et al. 2017 \\
\hline Being non-compliant with prescribed medications & 2.99 & $1.01,8.87$ & Moderate and positive & Salahuddin et al. 2020 \\
\hline Lifetime use of tobacco & 2.40 & $1.44,4.01$ & Moderate and positive & Araya et al. 2020 \\
\hline Khat chewing & 4.4 & $2.3,8.3$ & Strong and positive & Yitbarek et al. 2019 \\
\hline Substance use & 4.64 & $2.3,9.36$ & Strong and positive & Mossie et al. 2014 \\
\hline Having a history of recreational drug use & 13.67 & $6.42,29.13$ & Strong and positive & Salahuddin et al. 2020 \\
\hline CD4 count of 500 cells/dl or less & 2.37 & $1.52,3.68$ & Moderate and positive & Tsegaw et al. 2017 \\
\hline Having a CD4 count (cells/ $\mu \mathrm{l}) \leq 500$ & 1.61 & $1.11,2.39$ & Weak and positive & Araya et al. 2020 \\
\hline $\begin{array}{l}\text { Plasma HIV-1 RNA load between } 1.7 \log 10 \text { and } 3 \log 10 \\
\text { copies/ml }\end{array}$ & 2.2 & $1.1,4.3$ & Moderate and positive & Yitbarek et al. 2019 \\
\hline$\geq 3 \log 10$ copies $/ \mathrm{ml}$ & 7.5 & $2.6,21.5$ & Strong and positive & Yitbarek et al. 2019 \\
\hline Impairment in the activity of daily living & 7.19 & $1.73,21.83$ & Strong and positive & Belete et al. 2017 \\
\hline Have no communication about safe sexual intercourse & 2.88 & $1.61,5.16$ & Moderate and positive & Wubetu et al. 2021 \\
\hline Having co-morbid opportunistic infection & 7.48 & $4.1,13.64$ & Strong and positive & Mossie et al. 2014 \\
\hline Having comorbid depression and anxiety & 5.51 & $1.81,16.79$ & Strong and positive & Wubetu et al. 2021 \\
\hline Higher duration of HIV illness & 1.01 & $1.001,1.02$ & Weak and positive & Wubetu et al. 2021 \\
\hline Late clinical stage of the illness & 4.2 & $1.19,14.44$ & Strong and positive & Belete et al. 2017 \\
\hline Advancing stages of the disease & 3.558 & $1.41,9.01$ & Strong and positive & Animut et al. 2019 \\
\hline Clinical stage III of the disease & 5.6 & $1.7,19.2$ & Strong and positive & Yitbarek et al. 2019 \\
\hline
\end{tabular}

Table 5 Pooled odds ratio of HAND among people with HIV

\begin{tabular}{|c|c|c|c|c|c|}
\hline \multirow[t]{2}{*}{ Factors } & \multicolumn{2}{|c|}{ Estimates } & \multicolumn{2}{|c|}{ Heterogeneity } & \multirow{2}{*}{$\begin{array}{l}\text { Studies } \\
\text { pooled }\end{array}$} \\
\hline & $\begin{array}{l}\text { Pooled } \\
\text { effect } \\
\text { size }\end{array}$ & $95 \% \mathrm{Cl}$ & 12 & P-value & \\
\hline Older age & 2.97 & $2.12,3.82$ & $89.9 \%$ & $<0.001$ & {$[15,27-30]$} \\
\hline Being illiterate & 4.20 & $3.12,5.28$ & $94.7 \%$ & $<0.001$ & {$[11,15,27]$} \\
\hline $\begin{array}{l}\text { Substance } \\
\text { abuse }\end{array}$ & 6.28 & $0.73,11.82$ & $99.8 \%$ & $<0.001$ & {$[11,15,28,30]$} \\
\hline $\begin{array}{l}\text { Advanced } \\
\text { stages of the } \\
\text { diseases }\end{array}$ & 4.45 & $3.16,5.74$ & $95.2 \%$ & $<0.001$ & {$[12,21,30]$} \\
\hline
\end{tabular}

SNNPR reported a high prevalence of HAND. This discrepancy might be because of the cultural differences among regions and diverse measurement tools might attribute to the difference in the prevalence of HAND among these regions.

The prevalence of HAND was $40.98 \%$ for studies that used a sample size of more than 400 than for studies that used a sample size of less than 400 (36.10\%). This difference needs further investigation because the higher the sample size should yield the lower the prevalence rate. However, in this case, the higher sample size yields a higher prevalence, and the lower sample size yields a lower prevalence. 
In this study, aged people were three times at higher risk of developing HAND than people with 18-25 years. This finding was inconsistent with a meta-analysis study conducted in Sub-Saharan Africa [10]. The strong association observed in our study might reflect an increased vulnerability to HAND which may be intensified by lifestyle changes and physical changes during old age.

Aged people were about four times more likely to have HAND as compared to people with HIV who had primary and secondary education. This finding was supported by another study [34]. This could be due to literacy is significantly associated with virtually all neuropsychological measures, even though the correlation between education and neuropsychological test scores depends on the specific test. The impact of literacy is reflected in different spheres of cognitive functioning. Learning to read reinforces and modifies certain fundamental abilities, such as verbal and visual memory, phonological awareness, and visuospatial and visuomotor skills. Functional imaging studies are now demonstrating that literacy and education influence the pathways used by the brain for problem-solving. The existence of partially specific neuronal networks as a probable consequence of the literacy level supports the hypothesis that education impacts not only the individual's day-to-day strategies but also the brain networks [34].

People with HIV who used substances were six times more likely to have HAND as compared to people with HIV who didn't use the substance. The current study was consistent with another study [35]. HIV-associated neurocognitive impairment was associated with problematic methamphetamine use and higher plasma HIV RNA levels [35].

Moreover, the current study revealed that an advanced stage of the diseases or clinical stage III of HIV was 4.45 times more likely to have HAND than clinical stage I HIV. This might be because clinical stage III of HIV may affect the central nervous system and may expose the individual to develop different kinds of neurocognitive disorders.

\section{Limitations}

However, several limitations exist in this study. Firstly, screening tools were used to measure HAND and the same cut-off values of each screening tool were not used in all studies. So, we should cautiously apply the results to the population. Secondly, all of the included studies were performed in Ethiopia, which significantly affects the Africa representativeness of the estimates. Thirdly, a small number of studies were used in our subgroup analysis which may reduce the precision of the estimate. Fourthly, the researchers did not use a standard definition of neurocognitive impairment.

\section{Conclusion}

In this meta-analysis, the pooled prevalence of HAND in Ethiopia was high. Older age, substance abuse, advanced stages of the diseases, and having no education were the main determinants for HAND in Ethiopia. Therefore, based on our conclusions, health education and early screening of people living with HIV as well as training of health professionals working in the hospital on HAND are highly recommended.

\section{Abbreviations \\ AIDS: Acquired Immune Deficiency Syndrome; AOR: Adjusted odds ratio; ART: Antiretroviral therapy; IDHS: International HIV dementia scale; HAND: HIV asso- ciated neurocognitive disorders; HIV: Human immunodeficiency virus; MMSE: Mini-Mental State Examination tool; PRISMA: Preferred Reporting Items for Systematic Reviews and Meta-Analyses; SNNPR: Southern Nations, Nationali- ties, and Peoples'Region.}

\section{Acknowledgements}

The authors would like to acknowledge the work of the research teams whose publications were included in this systematic review and meta-analysis.

\section{Authors' contributions}

All authors contributed to the design of the study. YZ, BA, MW, and MN collected the data. YZ, BA, and MN conducted the quality evaluation of the included studies, and YZ, MW, and MN performed the data analysis. YZ and BA wrote the initial draft of the paper. All authors read and approved the final manuscript.

\section{Funding}

No funding was obtained for this study.

Availability of data and materials

All data generated or analyzed during this study are included in this manuscript.

\section{Declarations}

Ethics approval and consent to participate

Not applicable.

Consent for publication

Not applicable.

\section{Competing interests}

The authors declare that they have no competing interests.

\section{Author details}

${ }^{1}$ Department of Psychiatry, College of Medicine and Health Sciences, Wollo University, Dessie, Ethiopia. ${ }^{2}$ Department of Pharmacy, College of Medicine and Health Sciences, Wollo University, Dessie, Ethiopia. ${ }^{3}$ Department of Pediatrics and Child Health Nursing, College of Medicine and Health Sciences, Wollo University, Dessie, Ethiopia.

Received: 2 June 2021 Accepted: 13 December 2021

Published online: 19 December 2021

References

1. McArthur JC, Haughey N, Gartner S, Conant K, Pardo C, Nath A, et al. Human immunodeficiency virus-associated dementia: an evolving disease. J Neurovirol. 2003;9(2):205-21. 
2. Heaton R, Grant I, Butters N, White D, Kirson D, Atkinson J, Abramson, \& I., the HNRC Group, et al. The HNRC 500: neuropsychology of HIV-1 infection at different disease stages. J Int Neuropsychol Soc. 1995;1:231-51.

3. Organization WH. World Health Organization consultation on the neuropsychiatric aspects of HIV-1 infection. AIDS. 1990;4(9):935-6.

4. Antinori A, Arendt G, Becker J, Brew B, Byrd D, Cherner M, et al. Updated research nosology for HIV-associated neurocognitive disorders. Neurology. 2007;69(18):1789-99.

5. Saylor D, Dickens AM, Sacktor N, Haughey N, Slusher B, Pletnikov M, et al. HIV-associated neurocognitive disorder-pathogenesis and prospects for treatment. Nat Rev Neurol. 2016;12(4):234-48.

6. Clifford DB. HIV-associated neurocognitive disorders: epidemiology, clinical manifestations, and diagnosis. Uptodate Retrieved January. 2020;10:2021.

7. Focà E, Magro P, Motta D, Compostella S, Casari S, Bonito A, et al. Screening for neurocognitive impairment in HIV-infected individuals at first contact after HIV diagnosis: the experience of a large clinical center in Northern Italy. Int J Mol Sci. 2016;17(4):434

8. Robertson KR, Nakasujja N, Wong M, Musisi S, Katabira E, Parsons TD, et al. Pattern of neuropsychological performance among HIV positive patients in Uganda. BMC Neurol. 2007;7(1):1-7.

9. Hinkin $\mathrm{CH}$, Hardy DJ, Mason Kl, Castellon SA, Durvasula RS, Lam MN, et al. Medication adherence in HIV-infected adults: effect of patient age, cognitive status, and substance abuse. AIDS (London, England). 2004;18(Suppl 1):S19.

10. Habib AG, Yakasai AM, Owolabi LF, Ibrahim A, Habib ZG, Gudaji M, et al. Neurocognitive impairment in HIV-1-infected adults in SubSaharan Africa: a systematic review and meta-analysis. Int J Infect Dis. 2013;17(10):e820-31.

11. Araya T, Abebaw D, Belete A, Derajew H, Umer H. Prevalence and factors associated with neuro cognitive disorders among HIV-positive patients in Ethiopia: a hospital-based cross-sectional study. Ethiopian J Health Dev. 2020;34(1).

12. Belete T, Medfu G, Yemiyamrew E. Prevalence of HIV associated neurocognitive deficit among HIV positive people in Ethiopia: a cross sectional study at Ayder Referral Hospital. Ethiop J Health Sci. 2017;27(1):67-76.

13. Attonito JM, Dévieux JG, Lerner BD, Rosenberg R. Exploring substance use and HIV treatment factors associated with neurocognitive impairment among people living with HIV/AIDS. Front Public Health. 2014;2:105.

14. Vance DE, Fazeli PL, Dodson JE, Ackerman M, Talley M, Appel SJ. The synergistic effects of HIV, diabetes, and aging on cognition: implications for practice and research. J Neurosci Nurs. 2014:46(5):292.

15. Mossie TB, Tegegne MT. HIV dementia among HIV positive people at Debre markos hospital, Northwest Ethiopia. Am J Psychol Neurosci. 2014;2:18-24.

16. Pascal M, Gaspard T, Philomène N-K, Emmanuel Y, Avilah A-WP, Hortense H. Determinants of neurocognitive impairment in HIV in a cohort of patients on antiretroviral therapy followed in Bangui (Central African Republic). Neurosci Med. 2016;7(01):1.

17. Sumowski JF, Rocca MA, Leavitt VM, Dackovic J, Mesaros S, Drulovic $J$, et al. Brain reserve and cognitive reserve protect against cognitive decline over 4.5 years in MS. Neurology. 2014;82(20):1776-83.

18. Watkins CC, Treisman GJ. Cognitive impairment in patients with AIDSprevalence and severity. Hiv/aids (Auckland, NZ). 2015;7:35.

19. Wabel NT. Psychopharmacological aspects of catha edulis (khat) and consequences of long term use: a review. Psychiatry Behav Sci. 2011;1(4):187.

20. Sanmartí M, Meyer A, Jaen A, Robertson K, Tan N, Mapesi H, et al. HIVassociated neurocognitive impairment in stable people living with HIV on ART in rural Tanzania. HIV Med. 2021;22(2):102-12.

21. Debalkie Animut M, Sorrie MB, Birhanu YW, Teshale MY. High prevalence of neurocognitive disorders observed among adult people living with HIV/AIDS in Southern Ethiopia: a cross-sectional study. PLoS ONE. 2019;14(3):e0204636.

22. Liberati A, Altman DG, Tetzlaff J, Mulrow C, Gøtzsche PC, loannidis JP, et al. The PRISMA statement for reporting systematic reviews and meta-analyses of studies that evaluate health care interventions: explanation and elaboration. J Clin Epidemiol. 2009;62(10):e1-34.

23. Dévieux JG, Malow RM, Attonito JM, Jean-Gilles M, Rosenberg R, Gaston $\mathrm{S}$, et al. Post-traumatic stress disorder symptomatology and alcohol use among HIV-seropositive adults in Haiti. AIDS Care. 2013;25(10):1210-8.
24. Bornstein M, Hedges L, Higgins J, Rothstein H. Comprehensive metaanalysis. Englewood: Biostat; 2005.

25. Borenstein M, Hedges LV, Higgins JP, Rothstein HR. A basic introduction to fixed-effect and random-effects models for meta-analysis. Res Synthesis Methods. 2010;1(2):97-111.

26. Higgins JP, Thompson SG, Deeks JJ, Altman DG. Measuring inconsistency in meta-analyses. BMJ. 2003:327(7414):557-60

27. Schantell M, Taylor BK, Lew BJ, O'Neill JL, May PE, Swindells S, et al. Gray matter volumes discriminate cognitively impaired and unimpaired people with HIV. Neurolmage Clin. 2021;31:102775.

28. Tsegaw M, Andargie G, Alem G, Tareke M. Screening HIV-associated neurocognitive disorders (HAND) among HIV positive patients attending antiretroviral therapy in South Wollo, Ethiopia. J Psychiatric Res. 2017:85:37-41.

29. Salahuddin M, Manzar MD, Hassen HY, Unissa A, Hameed UA, Spence DW et al. Prevalence and predictors of neurocognitive impairment in Ethiopian population living with HIV. HIV/AIDS (Auckland, NZ). 2020;12:559.

30. Wubetu AD, Asefa KK, Gebregiorgis BG. Prevalence of neurocognitive impairment and associated factors among people living with HIV on highly active antiretroviral treatment, Ethiopia. HIV/AIDS (Auckland, NZ). 2021;13:425.

31. Yideg Yitbarek G, Mossie Ayana A, Bariso Gare M, Garedew Woldeamanuel G. Prevalence of cognitive impairment and its predictors among HIV/AIDS patients on antiretroviral therapy in Jimma University medical center, Southwest Ethiopia. Psychiatry J. 2019;2019.

32. Wang Y, Liu M, Lu Q, Farrell M, Lappin JM, Shi J, et al. Global prevalence and burden of HIV-associated neurocognitive disorder: a meta-analysis. Neurology. 2020;95(19):e2610-21.

33. Mavrodaris A, Powell J, Thorogood M. Prevalences of dementia and cognitive impairment among older people in sub-Saharan Africa: a systematic review. Bull World Health Organ. 2013;91:773-83.

34. Ardila A, Bertolucci PH, Braga LW, Castro-Caldas A, Judd T, Kosmidis MH, et al. Illiteracy: the neuropsychology of cognition without reading. Arch Clin Neuropsychol. 2010;25(8):689-712.

35. Weber E, Morgan EE, ludicello JE, Blackstone K, Grant I, Ellis RJ, et al. Substance use is a risk factor for neurocognitive deficits and neuropsychiatric distress in acute and early HIV infection. J Neurovirol. 2013;19(1):65-74.

\section{Publisher's Note}

Springer Nature remains neutral with regard to jurisdictional claims in published maps and institutional affiliations.

Ready to submit your research? Choose BMC and benefit from

- fast, convenient online submission

- thorough peer review by experienced researchers in your field

- rapid publication on acceptance

- support for research data, including large and complex data types

- gold Open Access which fosters wider collaboration and increased citations

- maximum visibility for your research: over 100M website views per year

At BMC, research is always in progress.

Learn more biomedcentral.com/submissions 